\title{
AS CIÊNCIAS DO LÉXICO: PROPOSIÇÕES PARA A PRÁTICA DOCENTE NO ENSINO DE LÍNGUAS INDÍGENAS
}

\section{THE SCIENCES OF LEXICON: PROPOSITIONS FOR TEACHER PRACTICE IN TEACHING INDIGENOUS LANGUAGES}

\author{
Paulo Hernandes Gonçalves da Silva ${ }^{1}$ \\ Francisco Edviges Albuquerque ${ }^{2}$
}

Resumo: O estudo aborda as perspectivas conceituais que envolvem as ciências do léxico e o processo de ensino e aprendizagem das línguas indígenas, seja a leitura, a escrita ou a fala. Objetiva esclarecer como ocorre o ensino de línguas para os indígenas no Brasil, a partir das políticas gerais e linguísticas, e, ainda com base na conceituação do léxico, como a unidade semântica mínima do discurso. A problemática abordada tem relação com as indagações para que a prática docente ocorra valorizando a linguagem falada pelas crianças indígenas. Os resultados alcançados são os subsídios para a valorização da língua materna e do ensino bilíngue, por meio dos conhecimentos das Ciências do Léxico, quer seja a Antroponímia, a Toponímia ou a Lexicografia, para uma proposta de ação docente mais adequada às necessidades dos povos indígenas.

Palavras-chave: Ciências do léxico; docentes; educação escolar indígena.

\begin{abstract}
The study approaches the conceptual perspectives that involve the lexical sciences and the process of teaching and learning of the indigenous languages, be it reading, writing or speaking. The objective was to clarify the occurrence of language teaching for indigenous peoples in Brazil, based on general and linguistic policies, and also based on the conceptualization of the lexicon as the minimal semantic unit of discourse. The problem approached is related to the inquiries so that the teaching practice occurs by valuing the language spoken by the indigenous children. Among the results obtained are the subsidies for the valorization of the mother language and bilingual education, by the knowledge of the Sciences of the Lexicon, be it the Anthroponymy, the Toponymy or the Lexicography, for a proposal of teaching action that is more appropriate to the needs of indigenous peoples.
\end{abstract}

Keywords: Lexical sciences; teachers; indigenous school education.

\section{CONSIDERAÇÕES INICIAIS}

Assegurar os direitos linguísticos das crianças nas escolas indígenas representa conhecer e reconhecer a realidade sociolinguística da comunidade e promover a discussão dessa realidade na escola, fortalecendo e valorizando a língua indígena em seu uso como língua de instrução, de comunicação, dos materiais didáticos e como objeto de análise e estudo, numa perspectiva que vem sendo debatida ao longo dos anos, conforme Grupioni (1994), uma vez que se objetiva esclarecer como ocorre o ensino de línguas para os indígenas no Brasil, a partir das políticas gerais e linguísticas, e ainda com base na conceituação do léxico como a unidade semântica mínima do discurso.

\footnotetext{
1 Doutorando em Letras pela Universidade Federal do Tocantins - UFT, TO, Brasil. E-mail: paulohg@ifto.edu.br.

2 Docente no programa de Mestrado e Doutorado em Letras, Universidade Federal do Tocantins - UFT, TO, Brasil. E-mail: fedviges@uol.com.
} 
No século XVI, após a aproximação dos portugueses aos povos nativos no Brasil, conforme cita Amoroso (2001), a educação escolar no país atingia comunidades indígenas, pela catequização feita pelos missionários jesuítas, e, já no século $X X$, pela integração coagida dos índios aos programas de ensino aplicado pelo extinto Serviço de Proteção aos Índios (SPI). Somente a partir da mobilização dos próprios indígenas, a situação começou a mudar gradativamente e a escola passou a ser vista como um espaço para o resgate da identidade étnica, linguística e cultural desses povos (CUNHA, 2008).

Logo, os professores indígenas devem participar de cursos de formação continuada que fortaleçam a construção de conhecimento e reflexão sobre a realidade da sua língua, do bilinguismo ou multilinguismo praticado em sua comunidade, para a possibilidade de formulação de estratégias no domínio da escola, para fortalecer e ampliar o uso da própria língua. Tem-se, na formação do docente indígena ou nãoindígena, um dos maiores alicerces do processo em questão, uma vez que a escola indígena se reveste em muitos significados para a cultura do povo (BRASIL 2005).

Abordar a realidade de um povo indígena específico não é a pretensão da pesquisa, mas sim trazer à luz dos estudiosos, a compreensão dos fatos a que nos propusemos, sobre o processo de educação escolar indígena. Um estudo que se justifica no processo linguístico em que o léxico é o patrimônio social da comunidade por excelência, conforme estabelece Biderman (2001), dada a relevância de uma língua para o seu povo, quando se observa que a língua desses povos vive a condição de língua minoritária frente à língua portuguesa.

Conforme Biderman (2001), o léxico é o patrimônio social porque resulta das experiências vivenciadas e aglomeradas pelas sociedades e culturas diacronicamente, inclusive confirmando como ocorre o processo de recriação e mudança do processo linguístico ao longo dos tempos, permitindo a expansão, a redução ou, até mesmo, a incorporação vocabular de uma língua para outra.

Por fim, é da natureza humana categorizar e nomear os seres e os objetos que a cercam, à medida que o universo do qual é parte integrante e determinante precisa ser conhecido e estruturado. Assim, conforme estabelecido por Neves (2010), é a partir do ato de nomear que se gera o léxico das línguas naturais, que vai se processando por meio de atos sucessivos de cognição da realidade e de categorização da experiência cristalizada em signos linguísticos.

\section{AS POLÍTICAS LINGUÍSTICAS PARA OS INDÍGENAS BRASILEIROS}

Existe muito trabalho educacional e linguístico a ser feito e construído no sentido da universalização da oferta de uma educação escolar de qualidade para os povos indígenas, que coadunem com os projetos desses povos, quanto ao futuro e autonomia, 
e, principalmente, que garantam sua inclusão no universo dos programas governamentais ligados à aprendizagem (BRASIL, 2005).

Implementar avanços na prática pedagógica específica para os povos indígenas, segundo Rizzini (2004), é um processo em curso que exige vontade política e medidas palpáveis para sua concretização. Quando se analisa, em plano de instituições governamentais, nota-se que ocorrem muitas ações, entretanto, são pacatas as iniciativas que garantam uma escola de qualidade.

Historicamente, o Brasil é um país multilíngue. Antes mesmo da chegada dos colonizadores portugueses, segundo Rodrigues (1993), a diversidade de línguas indígenas aqui faladas era imensa. Estima-se que eram cerca de 1.200 línguas. Durante o período de colonização, deslocaram para o país, além do português, línguas africanas com os negros, oriundos do tráfico para escravidão, e as primeiras línguas de povos imigrantes europeus, que se tornariam mais diversas nos séculos posteriores, criando essa miscelânea linguística.

A diversidade de línguas que convivem no território nacional envolvendo questões de acesso à informação e ao ensino, quando se fala em educação escolar indígena, tem muitas complexidades. E muito embora seja um país multilíngue, Faraco (2002) traz observações que o Brasil, de um modo geral, reconhece-se como unilíngue, face à confusão entre hegemonia e unicidade.

Apesar desse panorama, em relação às línguas indígenas, uma parcela da sociedade, incluindo lideranças indígenas, educadores, pesquisadores, políticos e organizações não governamentais tem promovido mobilizações cada vez mais fundamentadas e persistentes para influenciar políticas linguísticas no país, embora os resultados dessa atuação ainda sejam considerados incipientes (FARACO, 2002).

Quanto às especificidades do ensino bilíngue em escolas indígenas, sejam do financiamento a pesquisas para documentação de línguas em extinção, da revitalização de línguas ou das variedades de línguas e do investimento governamental em material didático específico para a educação indígena, o assunto requer uma discussão mais aprofundada, uma vez que, ao envolver a questão linguística, torna-se necessário o respeito aos conhecimentos, às tradições e aos costumes de cada povo, valorizando e fortalecendo a identidade étnica (SILVA, 1999).

Silva (1999) reitera o imperativo de uma outra educação formal para os povos indígenas, decorrente da situação de contato com a sociedade nacional. Desejam-se diferentes tipos de escolas para o atendimento das reivindicações dos diversos povos indígenas em nosso país. A escola não pode ser pensada homogeneamente, ela precisa ser arquitetada, mentalizada, organizada e construída diferentemente para cada povo que a requer. Entendendo o termo "construção" em todas as suas acepções, sejam físicas, pedagógicas e, principalmente, para as relações interpessoais, para que cada currículo ali possa ocorrer. 
Quanto aos marcos legais, a política educacional direcionada para os indígenas principiou a se modificar no Brasil a partir da Constituição Federal promulgada em 1988, em que, no seu artigo 210 (BRASIL, 1988), mesmo reafirmando a imposição da língua portuguesa no ensino fundamental brasileiro, colocada em prática desde o século XVIII, pelas prerrogativas de Marquês de Pombal, assegurou às comunidades indígenas a possibilidade de também utilizar, na educação formal, as suas línguas maternas, o que se configura como uma primeira indicação de mudança no planejamento para as línguas minoritárias brasileiras, pois se vê, ali, a abertura para o seu uso como meio instrucional (ALFARO, 2001).

A partir da criação da Lei de Diretrizes e Bases (LDB) da Educação Nacional (Lei 9.934/1996), e, principalmente, pelo exposto nos capítulos 78 e 79, nos quais se observa a proposição de um ensino voltado para os índios, apreendem-se novos ares direcionados ao país. A LDB estipulou que a União precisa, no aspecto da obrigatoriedade, desenvolver programas de ensino e pesquisa para oferecer educação escolar diferenciada, bilíngue e intercultural aos povos indígenas (BRASIL, 1996).

Em síntese, a LDB apresentou dispositivos que proporcionaram aos indígenas a recuperação de suas memórias históricas, a reafirmação de suas identidades étnicas e a valorização de suas línguas e conhecimentos tradicionais. Vê-se o planejamento para que o status das línguas indígenas fosse respeitado, e, por isso, colocou-se o ensino bilíngue apoiado pelo Estado, começando a se consolidar os novos rumos desejados pelos povos e estudiosos (MAHER, 2007).

Por sua vez, Cunha (2008) enfatiza que, além do planejamento do corpus da língua, com a sua documentação, e do planejamento de status, com o seu uso como língua de instrução, em muitos, casos no Brasil, é urgente um planejamento também para o processo de aquisição para tais línguas. Pois, para ele, é preciso que as crianças indígenas aprendam e façam uso do idioma de seus ancestrais e ele não seja extinto com a morte dos índios mais velhos que ainda o falam.

Para o Ministério da Educação e Cultura - MEC (BRASIL, 2005), ocorrem, aproximadamente, 170 línguas indígenas em uso nas comunidades de 210 etnias brasileiras. Porém é necessário o estudo para precisar quais das 2.322 escolas indígenas do país apresentam currículos bilíngues. O MEC evidencia que algumas comunidades utilizam, há algum tempo, a língua indígena na escola; em outras, a língua indígena está sendo reintroduzida; algumas abarcam mais de uma língua indígena ou também o espanhol, no caso de povos das fronteiras; e existem, inclusive, comunidades monolíngues em que o professor trabalha na língua local e, em momento posterior, internaliza o português como segunda língua.

Após as abordagens anteriores, nota-se que elaborar políticas linguísticas, para um país com longos períodos da história caracterizados pela negação da língua indígena e pelo desprezo com as políticas públicas, não é uma empreitada simplificada. A extensão territorial e as questões de cada grupo de falantes e de cada comunidade 
indígena evidenciam os imensuráveis desafios que devem ser solucionados, ou pelo menos enfrentados. Por outro lado, as políticas linguísticas são processos em que se movimentam grupos de pessoas com interesses e visões bastante diferenciadas e que apresentam-se como tarefa complexa, requerendo muitos cuidados, afinco e comprometimento (BRAGGIO, 2001).

As proposições mostram que não há como se falar em um exclusivo modelo de política linguística no país, como foi feito no período colonial, em que se aplicava o paradigma assimilacionista, com os ensinamentos dos missionários jesuítas, uma vez que o objetivo era construir um universo de conceitos cristãos, adequando o léxico indígena, no qual termos enraizados nas tradições religiosas dos nativos foram silenciados, porque eram considerados objeto passivos de erradicação, já que compunham partes das idolatrias (ALFARO, 2001).

Conforme preconiza o Referencial Curricular Nacional para as Escolas Indígenas - RCNEI (BRASIL, 1998), a língua indígena oral precisa se tornar a língua escrita de instrução predominante naquelas situações que dizem respeito aos conhecimentos étnicos e científicos tradicionais. Isso é relevante, segundo Maher (2007), para que, além da oralidade, possam aumentar sua competência escrita em língua indígena.

Além de ser a língua de instrução, a língua indígena deve estar inserida no currículo, no caso de comunidades bilíngues, como uma de suas disciplinas. Será a ocorrência da língua indígena como primeira língua, possibilitando que se desfrute dos direitos linguísticos que lhe são cabíveis como cidadãos, imposto pela constituição, além de permitir prestígio ao falante da referida língua materna (MAHER, 2007).

Favorecer o desenvolvimento das línguas indígenas na forma escrita é preciso. Além da oralidade, a escrita deve ser um mecanismo para o indígena compreender o mundo à sua volta, para que, a partir de sua realidade, possa compreender, também, o mundo onde a língua majoritária é falada (BORTONI-RICARDO, 2004).

A principal atividade desenvolvida pela escola para formação dos alunos deve ser a leitura. Isso se fundamenta nos pressupostos de Cagliari (2003), ao evidenciar que é muito mais importante saber ler do que saber escrever. Com pensamento idêntico, Albuquerque (2012) enfatiza que ensinar a criança indígena a ler na própria língua é essencial para a formação de bons leitores indígenas. A criança indígena que fala numa variedade de sua língua, diferente da que a escola usa e que aprende que leitura deve ser fundamentalmente feita no dialeto da escola, conduzirá esse tipo de hábito para a vida e, quando for ler, precisará fazer um esforço muito grande para conciliar velocidade de leitura e compreensão.

Segundo Albuquerque (2013), para a Lingüística que se encaminha, paulatinamente, conquistando o seu espaço nas discussões relativas ao ensino de língua materna, uma vez que seu objeto de estudo é a estrutura e o funcionamento das línguas naturais, deve ser adequadamente conhecido por quem, na escola, acompanha 
e orienta o processo de aquisição e domínio da modalidade escrita por parte dos falantes nativos de uma determinada língua. Neste caso específico, principalmente, o professor, seja indígena ou não-indígena.

O professor, portanto, deve estar intrinsicamente ligado à realidade do estudante indígena, para permitir a construção do mundo letrado e do léxico, conforme se observa em ALBUQUERQUE (2013, p. 13):

As crianças indígenas refletem sobre a sua língua. Desde muito cedo elas contam com uma grande capacidade de analisar a linguagem, aliás, é isto o que elas fazem o tempo todo quando estão aprendendo a falar. Muitas são as oportunidades em que podemos observar a sua criatividade para encontrar soluções quanto ao arranjo da linguagem para comunicar-se.

É por isso, portanto, que as discussões do processo de alfabetização, leitura e escrita de povos indígenas requerem, cada vez mais, a importante presença dos linguistas, constituindo-se como contribuição para a ressignificação da alfabetização nas escolas indígenas, onde a compreensão de teorias sobre os processos de aquisição da leitura e da escrita passa a ser fator principal para a escolha de uma metodologia adequada (ALBUQUERQUE, 2013).

\section{A PRÁTICA DOCENTE: CONTRIBUIÇÕES DAS CIÊNCIAS DO LÉXICO PARA OS INDÍGENAS}

Ao utilizar os conhecimentos da Lingüística, segundo Albuquerque (2013), o professor passa a ver a criança como sujeito do processo de aquisição da leitura e da escrita em língua materna e portuguesa, ou seja, um sujeito ativo que, ao adentrar a escola formal, ainda não possui uma representação do que seja ler e escrever, visto que possui uma tradição de língua oral. E, nessa perspectiva, conhecer o léxico, que é inerente ao patrimônio social de um povo, permitirá ao estudante um vislumbrar mais coerente do que seja leitura e escrita.

Com a aplicação da Lexicologia, Antroponímia, Lexicografia e da Toponímia apresenta-se um olhar ao processo de ensino e aprendizagem para os povos indígenas em sua língua materna. Nota-se, segundo Andrade e Dick (2012), que a busca por possibilidades inovadoras e transformadoras do fazer docente para o ensino de língua, seja na perspectiva interdisciplinar ou transdisciplinar, deve ocorrer com 0 aprofundamento nas perspectivas da linguagem, da língua e do léxico, aqui, entendido de forma resumida como "palavra".

\subsection{A Lexicologia}

As ciências do léxico, conforme Sapir (1961, p. 51), configuram-se como testemunhas de uma sociedade, devido à sua condição de ser resultante das experiências vividas e acumuladas pelas sociedades e culturas através dos tempos: 
Que o léxico assim reflita em alto grau a complexidade da cultura é praticamente um fato de evidência imediata, pois o léxico, ou seja, o assunto de uma língua, destina-se em qualquer época a funcionar como um conjunto de símbolos, referentes ao quadro cultural do grupo. Se por complexidade de uma língua se entende a série de interesses implícitos em seu léxico, não é preciso dizer que há uma correlação constante entre a complexidade linguística e a cultural.

É na experiência cotidiana, em meio às vivências socioculturais, que o ser humano armazena na memória novas palavras em seu acervo lexical individual. Esse processo é contínuo e perpassa por toda a sua vida, situação em que são papéis da instituição escolar e do professor a motivação para a construção desse campo lexical (BIDERMAN, 2001).

Segundo Genouvrier e Peytard (1985), na construção de processos linguísticos, a escola tem dois papeis: o primeiro é promover indivíduos comunicativamente competentes; o segundo, é contribuir para o aumento do léxico individual do estudante. Nota-se na prática, principalmente em línguas minoritárias, que o professor não tem mecanismos para favorecer esse enriquecimento lexical do aluno. Sabe-se, inclusive, que, em ato de fala, nenhum indivíduo utiliza a totalidade de seu léxico.

Biderman (2001) corrobora com a afirmação do léxico se constituir como um patrimônio histórico, social e cultural das sociedades. Ao se considerar a dimensão social da língua, o léxico atua como patrimônio social da comunidade, complementado por outros símbolos da herança cultural. Pode-se afirmar que essa riqueza léxica é transmitida de geração para geração, por meio da qual os indivíduos de cada geração podem pensar e exprimir suas emoções e pensamentos, que se iniciou, prioritariamente, com o simples ato de nomear as coisas ao redor de cada indíviduo.

Quando se fala em léxico no ensino para indígenas, há de se lembrar que o contato linguístico entre comunidades indígenas e não indígenas - muitas vezes com escolas regulares situadas próximo a aldeias - não pode deixar de produzir efeitos na formação educativa de crianças e jovens sobre o conhecimento linguístico e cultural do povo indígena. Não apenas porque se queira avigorar a contribuição do elemento indígena à cultura brasileira e ao léxico da língua portuguesa, mas, principalmente, porque o professor deve ser capaz de promover os adequados encaminhamentos, quando se trata de educação escolar bilíngue para povos minoritários (NEVES, 2008).

\subsection{A Antroponímia}

Quanto à aplicação da Antroponímia, aqui entendida como estudo dos nomes próprios das pessoas, conforme Dick (1992), vale afirmar, que esse elemento pode ser utilizado como facilitador do processo de alfabetização, seja para crianças indígenas e não-indígenas. Apreende-se na consideração de Silva (2008), o entendimento de que escrita e leitura do nome próprio é extremamente importante para as crianças. Elas 
passam a perceber o nome como o primeiro indício de formação da sua identidade e, principalmente, que as diferencia dos outros indivíduos.

Nos pressupostos de Dick (1992), o estudo da antroponímia exerce o papel de apropriados registros do cotidiano, revelado em atitudes e posturas sociais, específicas a determinados grupos humanos, pois os nomes das pessoas - antropônimos remetem desde questões sentimentais até as mais imensuráveis e complexas concepções sociológicas, culturais, religiosas, linguísticas, dentre outras. Com essa prerrogativa, o léxico antroponímico passa a ser compreendido como um indicador línguo-cultural, no qual a língua retrata a visão de mundo de um povo e evidencia a interrelação que se estabelece entre o linguístico e o mundo biossocial.

O processo de formação identitária da criança começa a acontecer no convívio com outras pessoas, com quem interage. No ambiente familiar, ela tem as primeiras matrizes de socialização. Depois, ao participar de outros espaços sociais, como festas, igrejas, clubes e feiras - no caso da criança não-indígena - e da participação em festas, rituais, mata, rios, veredas e estradas - no caso da criança indígena - os elementos apreendidos resultam numa diversidade étnica e cultural (SANTOS, 2010).

Segundo Santos (2010), quando as crianças começam a frequentar a instituição escolar, e entram em contato com a escrita de seus nomes, com uso de materiais escolares pessoais e coletivos, com a compreensão de reproduções gráficas de pinturas, da retratação da natureza à sua volta, da experiência matemática mais simples, passam a construir, internamente, condições para descobrir a base alfabética da escrita com compreensão e significado.

A utilização de recursos comunicativos se fortalece nesse momento, pois se potencializam o desenvolvimento da linguagem e o domínio da língua oral. Ao conviver e interagir com a linguagem escrita em sua vida social, a criança observa, pensa, faz perguntas, cria hipóteses, experimenta, toma decisões, faz cálculos, e cria conclusões, viabilizando o desenvolvimento de pensamento e da linguagem (MORAIS, 2012).

A formação da identidade da criança acontece em vários ambientes, conforme Ferreiro e Teberosky (1989). Antes de ingressarem na escola, as crianças sabem muito sobre a linguagem, mesmo não tendo aprendido a ler e escrever, elas possuem contato direto com a fala por intermédio do seu ambiente familiar, e é nesse ambiente inicial que as outras pessoas começam a falar seu nome, este é o primeiro aspecto, para a criança, do seu processo de individualidade.

Ferreiro e Teberosky (1989) tornam relevante a temática aqui tratada, pois, em seus estudos, os antropônimos são tidos como a primeira forma de escrita dotada de estabilidade, como protótipo e base para toda escrita posterior, em muitos casos, cumpre uma atenção muito especial na psicogênese, no processo do ser e de aceitar o ser do próximo. Por isso, vale a consideração de que o nome da criança é uma palavra 
que apresenta forte conteúdo significativo, emocional e de inclusão, sendo o primeiro sinal de identidade e reconhecimento infantil de si e do outro.

Essas proposições não são diferentes; para Santos (2008), nota-se que, em seus estudos, a identidade faz parte de cada indivíduo, ela diferencia as pessoas, começando pelo nome. E, mesmo existindo várias pessoas com nomes iguais, o nome é único para cada individuo que o detém. As diferenças, portanto, estão nas características físicas, no modo de agir, de pensar, e, principalmente, na história pessoal de cada um.

Quando a criança entra na educação escolar, ela aumenta seu universo imaginário e real, ela redimensiona a quantidade de nomes próprios em seu arcabouço lexical, pois o convívio com outras crianças fará com que ela adquira conhecimentos sobre realidades diversificadas, vendo as diferenças, percebendo as semelhanças, independente de etnias ou aspectos culturais (SANTOS, 2008).

\subsection{A Toponímia}

De maneira idêntica, chegada a oportunidade de abordar a Toponímia como elemento importante no processo de construção da aprendizagem de leitura e escrita, enfatiza-se que ela, conceitualmente, é a denominação para lugares, zonas, regiões, localidades, cidades, subúrbios, países ou povoações, ou de qualquer entidade geográfica ou topográfica de interesse público ou histórico (TIBIRIÇÁ, 1997).

Assim, conforme cita Carvalhinhos (2005), o nome carrega em si aspectos do lugar a que está vinculado, uma vez que o topônimo abrange não somente o nome de um lugar, mas o lugar em si. É, por isso, que o nome e o significado dos lugares são essenciais para a solidificação identitária de um grupo. Os topônimos, ainda segundo Tibiriçá (1997), avigoram fortemente as sugestões de identidade ou de estrutura que podem estar concentradas na própria condição física ou geográfica.

São nos topônimos que se traduzem o simbolismo, a história, a identidade e as peculiaridades de uma dada comunidade. Dessa maneira, a Toponímia só pode ser compreendida a partir de elementos de diversas ciências, como a Linguística, a História, a Geografia, Antropologia, Sociologia, Filosofia, dentre tantas outras, que corroboram para o entendimento de um processo único, compreendido como os lugares possuindo sua vida própria (ANDRADE; DICK, 2012).

O aprofundamento do estudo dos nomes de lugares nos interliga a diferentes áreas do conhecimento, o que permite um procedimento participativo para o estudo da história de um povo ou comunidade. O processo comunicativo permite que se conheça não somente os fatos acontecidos em um específico lugar, mas como esses acontecimentos são e foram influentes na formação e na nomeação daquela localidade. Assim, os topônimos apregoam relações diretas entre o homem e o espaço geográfico, uma vez que o ato de designar (nomear) é fundamentalmente humano, estabelecendo 
uma conexão cultural, proporcionalmente ligada à ocupação, posse e conhecimento do local ou da área nomeada (CORRÊA; ROSENDAHL, 1998).

A identidade cultural é, para Oliveira (2001), uma espécie de sentimento de pertencimento, haja vista, pela obliquidade antropológica, a identidade é relacionada às experiências e às diversas fontes de significado de um povo. A identidade vislumbrada nos topônimos movimenta valores, bem como os sentimentos, a fé, as crenças e diversos outros fatores vigentes nas diversas comunidades, apresentando-se como reflexo da convivência humana.

Os valores intrínsecos da identidade são constituídos por diversos modos de percepções, resultando em experiências e interpretações únicas, pois integram paisagens, sentimentos, possibilidades e manifestações. Os indivíduos mantêm relações com os nomes de lugares, que resultam no sentimento de pertencimento, evidenciando a prerrogativa que o conhecimento do contexto histórico e da etimologia (origem) dos nomes só reforça os laços afetivos construídos pela localidade (ANDRADE, 2006).

O resultado e a simbologia do topônimo são determinados pelas características físicas do local ou pelas impressões, crenças e sentimentos do denominador:

A aproximação do topônimo aos conceitos de ícone ou de símbolo, sugerido pela própria natureza do acidente nomeado, [...] vai pôr em relevo outras das características do onomástico toponímico, qual seja não apenas a identificação dos lugares mas a indicação precisa de seus aspectos físicos ou antropoculturais, contido na denominação (DICK, 1990, p. 24)

Gonçalves (2007) esclarece que, por meio do ato de batizar os lugares com nomes, que se criou a identidade, o sentimento de pertencimento e a territorialidades, que, de forma paulatina, foram aceitas pelas comunidades. Os nomes de lugares e sua dimensão cultural adquirem uma pluralidade com simbolismos e identidades que são corresponsáveis pelas expressões dos valores individuais.

Por conseguinte, na educação escolar, é necessário fazer o estudante perceber que todos os lugares habitados têm nome, e que esse nome é uma herança muito preciosa das culturas passadas (GONÇALVES, 2007). Na fase de alfabetização, às crianças, devem ser repassadas, gradativamente, que cada lugar possui suas práticas, rotinas, costumes e valores. Tem-se, a partir daí, a concretização da sua identidade consigo e com o espaço em que habita, de um mundo real para um mundo letrado.

\section{A PROPOSTA DE CONSTRUÇÃO DE GLOSSÁRIO: UMA ABORDAGEM LEXICOGRÁFICA}

A Lexicografia, tida como a prática de construir dicionários, requer um considerável entendimento de lexicologia, que se configura em compreender os itens lexicais em sua constituição morfológica, semântica e fonológica. A Lexicografia, 
portanto, é a ciência responsável pelo desenvolvimento de métodos e técnicas de produção das obras dicionarísticas na sua variedade de formas, sejam monolíngues, bilíngues, semibilíngues, escolares, acadêmicos, gerais, infantis, multilíngues, técnicocientíficos, dentre outras (FARGETTI, 2013).

A proposição da Lexicografia é muito mais técnica e científica que a simples construção de um glossário, em que o professor de educação básica se propunha a fazer para facilitar o processo de ensino e aprendizagem da leitura e escrita de uma língua indígena. Assim, defende-se a importância de se construir um glossário para o fim citado, face ao relevante papel desempenhado pelo léxico de uma língua no estabelecimento da relação entre língua e cultura. É com essa prerrogativa que Isquerdo (2001, p. 91) estabelece:

Partindo-se do princípio de que investigar uma língua é investigar
também a cultura, considerando-se que o sistema linguístico,
nomeadamente o nível lexical, armazena e acumula as aquisições
culturais representativas de uma sociedade, o estudo de um léxico (...)
pode fornecer, ao estudioso, dados que deixam transparecer
elementos significativos relacionados à história, ao sistema de vida, à
visão de mundo de um determinado grupo. Deste modo, no exame de
um léxico (...) analisa-se e caracteriza-se não apenas a língua, mas
também o fato cultural que nela se deixa transparecer. Essa
perspectiva de análise favorece uma melhor compreensão do próprio
homem e da sua maneira de ver e de representar o mundo. Dessa
forma, tal defesa pressupõe conceber o léxico como o principal
articulador da relação entre língua, sociedade e cultura, o que decorre
da feição multifacetada que as unidades lexicais - entidades
linguísticas, pragmáticas e ideológicas - adquirem nos processos de
interação e, consequentemente, nas interligações que estabelecem
com outros universos além do linguístico.

Segundo Biderman (2001), conhecer o léxico é o início de todo o processo, pois a categorização linguística dos elementos presentes na realidade que circunda os narradores ocorre à medida que eles processam o conhecimento acerca dos referidos elementos. Torna-se, por conseguinte, um processo mental, de classificação e estruturação da realidade que os rodeia por meio de um registro mnemônico dos itens lexicais que a representam.

A história dos dicionários no Brasil, para Gava (2012), mistura-se à história do contato e às estratégias civilizatórias de conquista e pacificação, pois a língua indígena foi o primeiro obstáculo a ser eliminado em busca de território, riquezas minerais e almas a serem convertidas ao cristianismo. Elementos, como a vegetação, os animais, os rios, os objetos, até então desconhecidos, possuíam seus nomes indígenas e nenhuma relação com a ciência europeia, o que explica a necessidade de verbetes enciclopédicos e onomasiológicos para descrevê-los.

O dicionário de língua registra a norma lexical corrente na sociedade, por isso o professor com essa proposição deve fazer um estudo sobre o papel do lexicógrafo, pois este é um profissional que deve selecionar os verbetes que constituirão as entradas no glossário proposto, com base em um corpus de referência não tão complexo, partindo 
de listas mais simplificadas em que se apresentam plantas, rios, animais, antropônimos, topônimos, fenômenos da natureza, dentre outros, que uma vez organizados, sistematicamente, permitirão ao estudante o olhar inicial para o léxico de sua língua. Segundo Biderman (2001), o ato de documentar e descrever será muito significativo para a aprendizagem.

No tocante à confecção de obras lexicográficas, aqui visto apenas como um projeto de ensino entre seus falantes, deve perpassar por um momento de atenção à ortografia na elaboração de léxicos. Sendo um glossário monolíngue, o objeto aqui proposto, e tendo um formato de lista, o que contraria as ideias de Fargetti (2013), como se configuram a maioria dos dicionários indígenas no país, será de grande relevância, enquanto material didático. Assim, os aspectos gramaticais, a discussão de pronúncias, prosódia, questões de polissemia e homonímia, entre outros, são aspectos que requerem um estudo mais científico no âmbito linguístico.

Por fim, a estratégia de trabalho do glossário visa desenvolver material didático capaz de receber vocábulos corriqueiros da língua do povo em que se promove o ensino de leitura e escrita. Ressaltando, entretanto, que a confecção de um corpus e sua adequação em um dicionário não se trata de mera lista de palavras, mas sim do rigor cientifico, uma vez que o sistema léxico é a somatória de toda a experiência acumulada de uma sociedade e do acervo da sua cultura por intermédio dos tempos (NUNES, 2006).

\section{CONSIDERAÇÕES FINAIS}

Alinhado ao objetivo de esclarecer como ocorre o ensino de línguas para os indígenas no Brasil, a partir das políticas gerais e linguísticas, o presente estudo trouxe uma ponderação sobre a educação escolar indígena, principalmente quanto à questão linguística. Isso ocorreu pelo fato dos povos indígenas possuírem o direito a uma educação escolar específica, diferenciada, intercultural, bilíngue (ou multilíngue), conforme define a legislação brasileira vigente, acarretando a possibilidade dos povos indígenas se apoderarem da instituição escola,

Observou-se que a escola, na vida das crianças indígenas, aparece, então, como um espaço diferenciado de cultura e de relações sociais que têm como objetivo contribuir com a formação integral desses sujeitos, considerando-os em seus aspectos cognitivos, afetivos, motores e sociais.

Quanto às políticas indígenas, compreendeu-se que existem muitas diversidades que precisam ser respeitadas, face à pluralidade étnica e os anseios de ações e perspectivas para cada povo indígena. Por isso, não são condizentes com as realidades existentes, tais políticas que tratam os povos de forma generalizada, sem levar em conta suas peculiaridades em termos socioculturais, linguísticos e históricos. 
A apropriação dos antropônimos pode facilitar a construção da identidade individual do estudante indígena, pois o nome próprio é carregado de simbolismos, que, intencionais ou aleatórios, homenageiam e perpetuam o indivíduo. Daí o fato de ser comum entre os indígenas, encontrarmos nomes próprios com significados profundos e ligados a sentimentos (alma, vida, alegria, felicidade e elementos da natureza).

De maneira similar, é fundamental compreender os topônimos a partir dos diferentes significados, pois estes se organizam conforme proposto por um tempo e espaço, na perspectiva individual do pertencimento, sendo o lugar sobreposto por valores socioculturais, econômicos, políticos, dentre outros.

Com a construção de um glossário de uma língua, pode-se ajudar a percepção de diversos sentidos de uma unidade lexical dentro de um sistema linguístico, sendo importante, portanto, para o processo de ensino e aprendizagem, bem como para a leitura e escrita de um povo indígena. $E$ por isso, o direito a uma educação escolar indígena, concebida na afirmação das identidades étnicas, pela recuperação das memórias históricas e pela valorização das línguas, torna-se fundamental para cada povo indígena.

\section{REFERÊNCIAS}

ALBUQUERQUE, F. E. O processo de aquisição de leitura e escrita pelas crianças indígenas Apinayé. Revista Teoria e Prática da Educação, v. 16, n. 2, 2013.

\section{ALBUQUERQUE, F.E e ALMEIDA, S. de A. Educação escolar indígena e} diversidade cultural (Orgs.). Goiânia: Ed. América, 2012.

ALFARO, C. As políticas lingüísticas e as línguas ameríndias. Revista Liames, v. 1, 2001.

AMOROSO, M. R. A mudança de hábito: catequese e educação para índios nos aldeamentos capuchinhos. In: SILVA, A.L. (Org.). Antropologia, história e educação: a questão indígena e a escola. 2. ed. São Paulo: Global, 2001.

ANDRADE, K. dos S; DICK, M.V.de P.do A. A interdisciplinaridade no contexto da toponímia: reflexões iniciais de uma proposta aplicada ao ensino. In: ISQUERDO, Maria Aparecida; SEABRA, Maria Cândida T. C. de. Ciências do léxico. V. VI. Campo Grande: UFMS, 2012.

ANDRADE, K.dos S. Atlas toponímico de origem indígena do estado do

Tocantins. 2006. 210f. Tese (Doutorado) - Universidade de São Paulo, São Paulo, 2006.

BIDERMAN, M. T. C. As ciências do léxico. In: OLIVEIRA, A. M. P. P; ISQUERDO, A. $\mathrm{N}$. (Orgs.). As ciências do léxico: lexicologia, lexicografia, terminologia. v. 1. Campo Grande: Ed. UFMS, 2001.

BORTONI-RICARDO, S. M. Educação em Língua Materna. São Paulo: Parábola, 
2004.

BRAGGIO, S.L.B. Políticas e direitos linguísticos dos povos indígenas brasileiros. Revista Signótica, v. 14, n. 1, 2001.

BRASIL. Constituição (1988). Constituição da República Federativa do Brasil. Brasília, DF: Senado, 1988.

Ministério da Educação - MEC. Alfabetização e Diversidade. Referenciais para a formação de professores indígenas. 2. ed. Brasília: MEC/SECAD, 2005.

SINPRO, 1996

Lei de Diretrizes e Bases da Educação Nacional - 9394/1996. São Paulo:

Referencial Curricular Nacional para as Escolas Indígenas - RCNEI. MEC, Brasília: MEC, 1998.

CAGLIARI, L. C. Alfabetização \& linguística. São Paulo: Scipione, 2003.

CARVALHINHOS, P. de J. Hierotoponímia Portuguesa. De Leite de Vasconcelos às atuais teorias onomásticas. Estudo de Caso: as Nossas Senhoras. 2005, $375 \mathrm{f}$. Tese (Doutorado) - Universidade de São Paulo, São Paulo, 2005.

CORRÊA, R. L; ROSENDAHL, Z. Paisagem, tempo e cultura. Rio de Janeiro: EDUERJ, 1998.

CUNHA, R. B. Políticas de línguas e educação escolar indígena no Brasil. Educar, n. 32, p. 143-159, 2008.

DICK, M. V.de P. do A. A motivação toponímica e a realidade brasileira. São Paulo: Arquivo do estado de SP, 1990.

DICK, M. V.de P. do. A. Toponímia e antroponímia no Brasil: Coletânea de estudos. 3. ed. São Paulo: FFLCH/USP, 1992.

FARACO, C.A. Questões de política de língua no Brasil: problemas e implicações. Educar em Revista, n. 20, p. 13-22, 2002.

FARGETTI, C. M. Pesquisa de línguas indígenas - questões de método. In: F. A. Del Ré, F. \& A. Vieira (orgs.), Estudos linguísticos contemporâneos. Diferentes olhares. Araraquara/SP: Editora Cultura Acadêmica, 2013.

FERREIRO, E.; TEBEROSKY, A. Alfabetização em processo. São Paulo: Editora Cortez, 1989.

GAVA, Á. A. Plataforma Kuhi pei: proposta de um modelo de dicionário terminológico onomasiológico multilíngue para crianças, Português-Arara, Kadiwéu, Karitiana, Parintintin, Xavante, Zoró. 2012. Tese (Doutorado)- Universidade Estadual Paulista, São José do Rio Preto, 2012.

GENOUVRIER, E.; PEYTARD, J. Léxico e Vocabulário. In: ensino do português. Coimbra: Almedina, 1985. Linguística e

GONÇALVES, T.M. Cidade e Poética: um estudo de psicologia ambiental sobre o ambiente urbano. ljuí: Ed. Unijuí, 2007. 
GRUPIONI, L.D.B Benzi (org.). Índios no Brasil. Brasília: Ministério da Educação e do Desporto, 1994.

ISQUERDO, A. N. Vocabulário do seringueiro: campo léxico da seringa. In: ISQUERDO, A.N; OLIVEIRA, A.M.P.P.de. (Org.). As ciências do léxico: lexicologia, lexicografia, terminologia. v.1. 2.ed. Campo Grande: Ed. UFMS, 2001.

MAHER, T. M. Do casulo ao movimento: a suspensão das certezas na educação bilíngüe e intercultural. In: CAVALCANTI, M. C.; BORTONI-RICARDO, S. M. Transculturalidade, linguagem e educação. Campinas, SP: Mercado de Letras, 2007.

MORAIS, A. G. Sistema de Escrita Alfabética. São Paulo: Melhoramentos, 2012.

NEVES, J. G. Alfabetização intercultural: oralidade, escrita e bilinguismo em sociedades indígenas. Revista Espaço Acadêmico, n. 85, 2008.

NEVES, M. H. M. Ensino de língua e vivência de linguagem. São Paulo: Contexto, 2010.

NUNES, J. H. Dicionários no Brasil: análise e história. Campinas: Pontes Editores; São Paulo: FAPESP, 2006.

OLIVEIRA, P. S. Introdução à sociologia. São Paulo: Ática, 2001.

RIZZINI, I. O cidadão polido e o selvagem bruto: A educação dos meninos desvalidos na Amazônia Imperial. Rio de Janeiro: Universidade Federal do Rio de Janeiro, 2004.

RODRIGUES, A. Línguas indígenas: 500 anos de descobertas e perdas. São Paulo/SP: Delta, 1993.

SANTOS, M.G. O processo de alfabetização na educação infantil. Rio de Janeiro: UFRJ, 2010.

SANTOS, R. V. Impasses na relação do aluno com a escrita. 2008. Dissertação (Mestrado em linguística aplicada e estudos da linguagem) - Pontifícia Universidade Católica de São Paulo, São Paulo, 2008.

SAPIR, E. Lingüística como ciência. Rio de Janeiro: Livraria Acadêmica, 1961.

SILVA, M.M.M. Entre a letra e o nome: Alfabetização de alunos em situação de fracasso escolar a partir da intervenção de orientação psicanalítica. Dissertação (Mestrado em Educação) - Universidade Federal de Minas Gerais, Belo Horizonte, 2008.

SILVA, R.H.D.da. A autonomia como valor e articulação de possibilidades: $O$ movimento dos professores indígenas do Amazonas, de Roraima e do Acre e a construção de uma política de educação escolar indígena. Cadernos Cedes, v. 19, n. 49, p. 62-75, 1999.

TIBIRIÇÁ, L. C. Dicionário de Topônimos de Origem Tupi. São Paulo: Traço, 1997. 